\title{
Isolation, Characterization and Antimicrobial Screening of Betulinic Acid from the Stem Extract of Fadogia erythrophloea
}

\author{
J. M. Joshua ${ }^{1}$, A. O. Oyewale ${ }^{1}$, H. Ibrahim ${ }^{1}$ \\ ${ }^{1}$ Ahmadu Bello University, Faculty of Physical Sciences, Department of Chemistry, Zaria, Kaduna State, \\ Nigeria. \\ *Correspondents Author: oyewaleao@yahoo.co.uk, +2348022408198.
}

Received 07 January 2020; accepted 28 May 2020, published online 29 June 2020

\begin{abstract}
The stem bark of Fadogia erythrophloea (Rubiaceae) was extracted exhaustively using methanol by cold maceration. The crude extract was then sequentially partitioned into n-hexane, chloroform and ethyl acetate fractions. Purification of the chloroform fraction by column and preparative thin layer chromatography lead to the isolation of the pure compound. Structural elucidation using FTIR, ${ }^{1} H$ and ${ }^{13} \mathrm{C} N M R$ spectroscopic techniques confirmed that the isolated compound was betulinic acid (a lupanetype triterpene). The antimicrobial property of the compound against gram-positive and gram-negative microbes was evaluated using well diffusion method with commercial antibiotics; ciprofloxacin and fluconazole, as controls. The antimicrobial screening revealed sensitivity of $S$. aureus, S. faecalis, $B$. cereus, E. coli, $K$. pneumonia, S. typhi, S. dysenteriae, C. albicans, C. Krusei; with resistance of $S$. pyogenes, B. subtilis, $C$. ulceran, $P$. aeruginosa to the isolated compound. The zone of inhibition ranges from $25-30 \mathrm{~mm}$ with the highest against Escherichia coli and the lowest against Klebsiella pneumonia on which both control drugs were not sensitive. The MIC and MBC / MFC values ranges from $6.25-25$ $\mu \mathrm{g} / \mathrm{ml}$ and $25-50 \mu \mathrm{g} / \mathrm{ml}$ respectively. The in vitro anti-microbial screening of the isolated compound (betulinic acid) supports the ethno medicinal claim on the uses of Fadogia erythrophloea for the treatment of malaria, childhood fever, dysentery diarrhea, colic and constipation.
\end{abstract}

Key words: Fadogia erythrophloea, Antimicrobial, Chromatography, Maceration, Betulinic acid.

\section{INTRODUCTION}

Plants have been by far the most widely studied source of medicinal compounds, due to their limitless ability to synthesize bioactive substances, mainly, secondary metabolites [1]. This makes them remain an important source of new drugs, precursor for new drugs, and chemical entities [2-4]. Many of these metabolites are found to be unique to a particular organism. They may not be essentially needed for metabolism, but may be related to the function of environmental adaptation and also serve as defensive molecules against predation by microorganisms, insects and herbivores. Some of these metabolites are involved in plant odour (terpenoides), pigmentation (tannins and quinines), and flavour (Capsacin) [5,6]. However, these secondary metabolites give plants their medicinal value which is appreciated by human beings because of their great importance in health care of individuals and communities. Fadogia is a genus of flowering plants in the family Rubiaceae. The Rubiaceae family is characterized by the production of bioactive metabolites with great pharmacological potential such as iridoids, indole alkaloids, anthraquinones, terpenoids (diterpenes and triterpenes), flavonoids and other phenolic derivatives, with emphasis on production of bioactive alkaloids [7]. The number of described products, the structural diversity and pharmacological activities reported for various species of Rubiaceae demonstrates this family to be a promising source of new bioactive substances, which may give rise to new products as active molecules or even drug prototypes. Many of these plants have widespread use in folk medicine and some showed anti-inflammatory, analgesic, antibacterial, mutagenic, antiviral, antioxidant, effect on vascular diseases as well as activity on the central nervous system [8]. 


\section{MATERIALS AND METHODS}

\section{Collection and preparation of plant material}

The stem of Fadogia erythrophloea was collected from Anara forest in Zaria, Kaduna State, Nigeria. The plant was identified at National Research Institute for Chemical Technology (NARICT) Basawa, Zaria, Nigeria, with voucher number 0127 . The plant sample was air-dried at room temperature for 21 days and then pulverized using mortar and pestle. The pulverized plant was kept in an air tight container until it was required for use

\section{Extraction of plant material}

The pulverized plant (2 kg) was exhaustively extracted by cold maceration using methanol. The crude extract was then partitioned into; n-hexane, chloroform and ethyl acetate fractions respectively by sequential extraction using a separating flask [9]. The respective fractions were concentrated under vacuum using a rotary evaporator and later allowed to dry at room temperature to a constant weight.

\section{Isolation and purification}

The chloroform fraction was dissolved in chloroform then subjected to thin layer chromatography (TLC). The plate was developed using several solvent systems. The solvent systems of n-hexane / ethyl acetate (9:1) and n-Hexane / ethyl acetate (8:2) gave better separation of the components, and were used in the TLC monitoring of the Column. The chloroform fraction (10 g) was subjected to column chromatography on a silica gel (60 120 mesh) with gradient elution using $n$-hexane and ethyl acetate [10]. Eluents were collected in $50 \mathrm{ml}$ beaker and TLC was used to monitor the fractions. A total of 32 collections were made and pooled into 5 major fractions, based on their TLC profiles. Fractions $C_{3}$ and $C_{5}$ indicated significant proportion of the compound of interest and was further subjected to purification by preparative thin layer chromatography (PTLC) using the solvent system n-Hexane / ethyl acetate (7:3). A single homogenous spot was obtained on running the TLC with two different solvent systems n-hexane / ethyl acetate (9:1) and (8:2). This compound, coded (JFE), appeared as white amorphous substance after it was allowed to dry at room temperature. It was then subjected to spectral analysis.

\section{Characterization}

FTIR, ${ }^{1} \mathrm{H}$ NMR, and decoupled ${ }^{13} \mathrm{C}$ NMR spectroscopic techniques were used to elucidate the structure of JFE. The IR spectrum was recorded on FTIR-8400s (Shimadzu) at the Department of Chemistry, Ahmadu Bello University, Zaria; the ${ }^{1} \mathrm{H}$ NMR, and ${ }^{13} \mathrm{C}$ NMR spectra were recorded on a Bruker AVANCE spectrometer, $600 \mathrm{MHz}$ for the proton and 150 $\mathrm{MHz}$ for the carbon at School of Chemistry and Physics, University of Kwazulu Natal, Scottsville Pietermaritzburg, South Africa, in deuterated chloroform with TMS as internal standard.

\section{Antimicrobial activity studies}

The antimicrobial activities of JFE was determined using pathogenic microbes, in vitro. The microbes; Staphylococcus aureus, Streptococcus faecalis, Bacillus cereus, Escherichia coli, Klebsiella pneumonia, Salmonella typhi, Shigella dysenteriae, Candida albicans, Candida Krusei, Streptococcus pyogenes, Bacillus subtilis, Corynebacterium ulceran, and Pseudomonas aeruginosa, were obtained from the Department of Medical Microbiology, Ahmadu Bello University Teaching Hospital, Zaria, Kaduna State, Nigeria. The analysis was done using well diffusion method [11]. The antibiotics, Ciprofloxacin and Fluconazole were used as control.

The compound JFE $(0.001 \mathrm{mg})$ was dissolved in DMSO $(10 \mathrm{ml})$ to obtain a concentration of $100 \mu \mathrm{g} / \mathrm{ml}$. The stock solution was serially diluted to give $50 \mu \mathrm{g} / \mathrm{ml}, 25 \mu \mathrm{g} / \mathrm{ml}$, $12.5 \mu \mathrm{g} / \mathrm{ml}, \quad 6.25 \mu \mathrm{g} / \mathrm{ml}$ and $3.13 \mu \mathrm{g} / \mathrm{ml}$ concentrations. All media were prepared in accordance to manufacturer's instructions and sterilized by autoclaving at $121^{\circ} \mathrm{C}$ for 15 mins. The sterilized medium was seeded with the standard inoculum $(0.1 \mathrm{ml})$ of the test microbe. The inoculum was spread evenly over the surface of the medium by the use of a sterile swab. Using a standard cork of $6 \mathrm{~mm}$ in diameter, a well was cut at the center of each inoculated medium. Solution of the compound 
$(0.1 \mathrm{ml})$ was then introduced into the well on the inoculated medium. The incubation was made at were observed for any evidence of inhibition which will appear as a clear zone that is completely devoid of growth around the wells (zone of inhibition). The diameter of the zones were measured.

The minimum inhibitory concentration (MIC) was determined using nutrient broth dilution method. Muller Hinton broth was prepared in accordance to the manufacturer's instruction. The solution $(10 \mathrm{ml})$ was dispensed into the test tubes and was sterilized at $121^{\circ} \mathrm{C}$ for 15 mins. The broth was then allowed to cool. Mc-Farland's turbidity standard scale number 0.5 was prepared to give turbid solution. Normal saline $(10 \mathrm{ml})$ was dispensed into sterile test tube. The test microbe was inoculated at $37^{\circ} \mathrm{C}$ for $6 \mathrm{hrs}$. Dilution of the test microbe was done in normal saline until the turbidity marched that of Mc-farland's scale by visual comparison. At this point, the test microbes has a concentration of $1.5 \times 10^{8} \mathrm{cfu} / \mathrm{ml}$. Two-fold serial dilution of the compound was done in the sterile broth to obtain the concentrations of $50 \mu \mathrm{g} / \mathrm{ml}, 25$ $\mu \mathrm{g} / \mathrm{ml}, 12.5 \mu \mathrm{g} / \mathrm{ml}, 6.25 \mu \mathrm{g} / \mathrm{ml}$ and $3.13 \mu \mathrm{g} / \mathrm{ml}$. The initial concentration $(100 \mu \mathrm{g} / \mathrm{ml})$ was obtained by dissolving the compound $(0.001$ $\mathrm{mg})$ in sterile broth $(10 \mathrm{ml})$. Having obtained the different concentrations of the compound in the sterile broth, $0.1 \mathrm{ml}$ of the test microbe in the normal saline was then inoculated into the different concentrations. Incubation was made at $37^{\circ} \mathrm{C}$ for $24 \mathrm{hrs}$, after which the plates were observed for turbidity growth. The lowest concentration of the compound in the both which shows no turbidity was recorded as the minimum inhibition concentration.

MBC / MFC was carried so as to determine the concentration at which the test microbes were completely killed or only their growth was inhibited. Mueller Hinton agar was prepared, sterilized at $121^{\circ} \mathrm{C}$ for 15 mins then poured into sterile petri dish and was allowed to cool and solidify. The content of the MIC in the serial dilutions which did not show turbidity (clear) in the MIC test was then sub cultured onto the prepared medium. The plates were incubated at $37^{\circ} \mathrm{C}$ for $24 \mathrm{hrs}$ after which the plates of the media were observed for colony growth. MBC / MFC were the plates with the $37^{\circ} \mathrm{C}$ for $24 \mathrm{hrs}$. At the end of the incubation period, the plates lowest concentration of the compound without colony growth.

\section{RESULTS AND DISCUSSIONS}

\section{Characterisation}

JFE was isolated as a white amorphous solid (22.0 mg), with $R_{f}$ value of 0.44 in $n$ hexane / ethyl acetate (9:1) and a melting point ranging from $276-279^{\circ} \mathrm{C}$. The FTIR spectrum (Figure 2) revealed a strong broad band signal of O-H stretching at $3470.2 \mathrm{~cm}^{-1}$ and a strong signal at $1684.8 \mathrm{~cm}^{-1}$ for $\mathrm{C}=\mathrm{O}$ stretching of carboxylic acid (-COOH).

The ${ }^{1} \mathrm{H}$ NMR spectrum (Figure 3) showed six methyl signals at $\delta_{\mathrm{H}} 0.75,0.83,0.94$, $0.95,0.96$ and $1.69 \mathrm{ppm}$. A doublet of doublets was observed at $\delta_{\mathrm{H}} 3.19 \mathrm{ppm}$, characteristic of an $\alpha$-oriented hydrogen at C-3 of a $3-\beta$-hydroxy triterpene. Doublets for terminal methylene protons at $\delta_{\mathrm{H}} 4.74$ and $4.64 \mathrm{ppm}$ along with a methyl signal at $\delta_{\mathrm{H}} 1.69 \mathrm{ppm}$ further suggested that JFE is a lupane-type triterpenoid. Two multiplate were observed at $\delta_{\mathrm{H}} 3.00 \mathrm{ppm}$ and $\delta_{\mathrm{H}}$ $3.19 \mathrm{ppm}$ which were assigned to $\mathrm{H}-18$ and $\mathrm{H}-3$ respectively. Furthermore, a pair of oxymethylene doublets at $\delta_{\mathrm{H}} 3.70$ and $3.19 \mathrm{ppm}$, instead of a seventh methyl singlet around $\delta_{\mathrm{H}} 0.8$ ppm indicated the presence of a secondary hydroxyl proton in the molecule. The rest of the protons were overlapping aliphatic $\mathrm{CH}, \mathrm{CH}_{2}$, and $\mathrm{CH}_{3}$ groups [12].

The ${ }^{13} \mathrm{C}$ NMR Spectrum (Figure 4) revealed thirty signals (which further suggested compound JFE to be a lupane-type triterpenoid derivative) ranging from $14.7 \mathrm{ppm}$ to 179.9 ppm. This implies that there are thirty carbon atoms in the compound. A sp ${ }^{2}$ hybridized carbon atoms comprising the double bond of lupeol was observed at 150.4 and $109.7 \mathrm{ppm}$. Oxygenated carbon shifts were observed at $\delta 79.0$ and 179.9 ppm which represents a carbon carrying an alcoholic $(-\mathrm{OH})$ and carboxylic acid $(-\mathrm{COOH})$ groups respectively. The DEPT (Figure 5), in comparison with the decoupled ${ }^{13} \mathrm{C}$ revealed six methyl, eleven methylene, four methine and seven quaternary carbons. The spectra $\left({ }^{1} \mathrm{H}\right.$ and ${ }^{13} \mathrm{C}$ NMR) revealed a lupane-type triterpenoid with a hydroxyl and carboxylic acid groups at C-3 and C-28 respectively. 
On comparison with data from literature (Table 1) [12, 13], the compound was found to be $3 \beta$-hydroxy-lup-20(29)-en-28-oic acid (betulinic acid) (Figure

Table 1: Comparing the ${ }^{13} \mathrm{C}$ NMR and ${ }^{1} \mathrm{H}$ NMR spectra data of JFE with literature data for betulinic acid [12,13].

\begin{tabular}{|c|c|c|c|c|}
\hline Carbon & $\delta^{13} \mathrm{C}(\mathrm{JFE})$ & $\delta^{13} \mathrm{C}$ (Reference) & $\delta$ H (JFE) & \& H (Reference) \\
\hline 1 & 38.7 & 39.0 & 1.68 & \\
\hline 2 & 27.4 & 27.6 & 1.62 & \\
\hline 3 & 79.0 & 78.2 & 3.19 & 3.18 \\
\hline 4 & 38.9 & 39.0 & - & - \\
\hline 5 & 55.4 & 55.5 & 0.69 & \\
\hline 6 & 18.3 & 18.4 & $1.52,1.39$ & \\
\hline 7 & 34.4 & 34.5 & 1.38 & \\
\hline 8 & 40.7 & 40.8 & - & - \\
\hline 9 & 50.6 & 50.7 & 1.28 & \\
\hline 10 & 37.2 & 37.3 & - & - \\
\hline 11 & 20.9 & 21.0 & $1.26,1.43$ & \\
\hline 12 & 25.5 & 25.6 & $1.04,1.70$ & \\
\hline 13 & 38.4 & 38.2 & 2.20 & \\
\hline 14 & 42.5 & 42.5 & - & - \\
\hline 15 & 30.6 & 30.8 & 1.99 & \\
\hline 16 & 32.2 & 32.6 & 2.28 & \\
\hline 17 & 56.3 & 56.3 & - & - \\
\hline 18 & 46.9 & 47.1 & 3.00 & 3.00 \\
\hline 19 & 49.3 & 49.4 & 1.64 & 1.55 \\
\hline 20 & 150.4 & 150.9 & - & - \\
\hline 21 & 29.7 & 29.9 & 1.26 & \\
\hline 22 & 37.0 & 37.3 & $1.97,1.47$ & \\
\hline 23 & 28.0 & 28.2 & 0.96 & 0.93 \\
\hline 24 & 15.3 & 15.6 & 0.75 & 0.75 \\
\hline 25 & 16.1 & 16.1 & 0.83 & 0.82 \\
\hline 26 & 16.0 & 16.1 & 0.95 & 0.97 \\
\hline 27 & 14.7 & 14.7 & 0.97 & 0.96 \\
\hline 28 & 179.9 & 178.9 & - & - \\
\hline 29 & 109.7 & 109.4 & $4.74,4.64$ & $4.73,4.60$ \\
\hline 30 & 19.4 & 19.4 & 1.69 & 1.68 \\
\hline
\end{tabular}




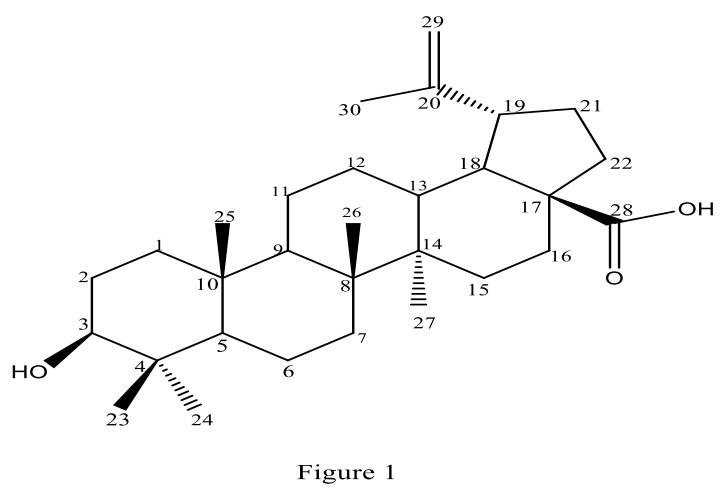

\section{Antimicrobial screening}

Nine of the thirteen tested organisms, $S$, aureus, S. faecalis, B. cereus, E. coli, K. pneumonia, S. typhi, S. dysenteriae, C. albicans, and C. krusei were sensitive to Compound JFE (Table 2). Four tested organisms, S. pyogenes, B. subtilis, $C$. ulceran, and $P$. aeruginosa were however resistant to the compound. B. subtilis was resistant to compound JFE and the control antibiotics. $K$. pneumonia was sensitive to compound JFE but resistant to the controls.

Compound JFE was found to have zones of inhibition ranging from $25-30 \mathrm{~mm}$ with the highest against $E$. coli and the lowest against $K$. pneumonia on which both control drugs were not sensitive. The zones of inhibition of the control (from 25 to $39 \mathrm{~mm}$ ) were found to be comparatively greater than that of compound JFE for all the microbes except for $S$. aureus on which JFE was found to have the highest zone of inhibition compare to the control (Table 2). Table 3 showed the minimum inhibition concentration (MIC), which is the maximum concentration that will inhibit the growth but not kill the microbes. The lowest MIC value was found to be $6.25 \mu \mathrm{g} / \mathrm{ml}$ and it is against $E$. coli while the highest MIC value was found to be 25 $\mu \mathrm{g} / \mathrm{ml}$ against $S$. faecalis, $K$. pneumonia and $S$. typhi.
Table 3 showed the minimum bactericidal / fungicidal concentration (MBC / MFC) values of JFE, which is the minimum concentration that will completely kill the microbes. The lowest value was found to be 25 $\mu \mathrm{g} / \mathrm{ml}$ against $S$. aureus, E. coli, and C. albicans while the highest value was found to be 50 $\mu \mathrm{g} / \mathrm{ml}$ against $S$. faecalis, $B$. cereus, $K$. pneumonia, S. typhi, S. dysenteriae, and $C$. Krusei. C. albicans and C. krusei are responsible for candidiasis; $S$. aureus causes meningitis, scalded skin syndrome; E. coli is responsible for diarrhea, bacteremia; $S$. typhii is the causative agent for typhoid fever; $B$. cereus is responsible severe nausea, vomiting, and diarrhea; $S$. dysenteriae is responsible for dysentery and diarrhea; $K$. pneumonia causes intestinal, urinary and respiratory tract infection $[14,15]$. These results showed that JFE (betulinic acid) is an antimicrobial agent and supports the ethno medicinal claim on the uses of Fadogia erythrophloea for the treatment of malaria, childhood fever, dysentery, diarrhea, colic and constipation [16]. Furthermore, it adds to the reports on the variety of biological and medicinal properties exhibited by the isolated compound (betulinic acid), which are; antimalarial activity [17, 18, 19], antioxidant activity [20], anti-HIV activity, anti-cancer activity, antibacterial activity, anthelmintic activity, analgesic and anti-inflammatory activity [18]. 
Table 2: The sensitivity test and Zone of inhibition (mm) of Compound JFE on Microbes

\begin{tabular}{llllllc}
\hline Test Organism & \multicolumn{2}{c}{ JFE } & \multicolumn{2}{c}{ Ciprofloxacin } & \multicolumn{2}{c}{ Fluconazole } \\
& ST & ZI & ST & ZI & ST & ZI \\
\hline Staphylococcus aureus & S & 28 & S & 26 & - & - \\
Streptococcus pyogenes & $\mathrm{R}$ & - & $\mathrm{S}$ & 29 & - & - \\
Streptococcus faecalis & $\mathrm{S}$ & 26 & $\mathrm{~S}$ & 30 & - & - \\
Bacillus subtilis & $\mathrm{R}$ & - & $\mathrm{R}$ & - & - & - \\
Bacillus cereus & $\mathrm{S}$ & 27 & $\mathrm{R}$ & - & - & - \\
Corynebacterium ulceran & $\mathrm{R}$ & - & $\mathrm{S}$ & 31 & - & - \\
Escherichia coli & $\mathrm{S}$ & 30 & $\mathrm{~S}$ & 37 & - & - \\
Klebsiella pneumonia & $\mathrm{S}$ & 25 & $\mathrm{R}$ & - & - & - \\
Pseudomonas aeruginosa & $\mathrm{R}$ & - & $\mathrm{S}$ & 25 & - & - \\
Salmonella typhi & $\mathrm{S}$ & 26 & $\mathrm{~S}$ & 39 & - & - \\
Shigella dysenteriae & $\mathrm{S}$ & 27 & $\mathrm{~S}$ & 37 & - & - \\
Candida albicans & $\mathrm{S}$ & 28 & - & - & $\mathrm{S}$ & 34 \\
Candida krusei & $\mathrm{S}$ & 27 & - & - & $\mathrm{S}$ & 32 \\
\hline
\end{tabular}

KEY: S = Sensitive, R = Resistance, - = not determined, ST = Sensitivity, ZI = Zone of inhibition

Table 3: Minimum inhibition concentration (MIC) and Minimum bactericidal/fungicidal concentration (MBC) in $\mu \mathrm{g} / \mathrm{ml}$ of compound JFE on microbes

\begin{tabular}{lcc} 
Test Organisms & MIC & MBC / MFC \\
\hline Staphylococcus aureus & 12.5 & 25 \\
Streptococcus pyogenes & $0^{*}$ & $0^{*}$ \\
Streptococcus faecalis & 25 & 50 \\
Bacillus subtilis & $0^{*}$ & $0^{*}$ \\
Bacillus cereus & 12.5 & 50 \\
Corynebacterium ulceran & $0^{*}$ & $0^{*}$ \\
Escherichia coli & 6.25 & 25 \\
Klebsiella pneumonia & 25 & 50 \\
Pseudomonas aeruginosa & $0^{*}$ & $0^{*}$ \\
Salmonella typhi & 25 & 50 \\
Shigella dysenteriae & 12.5 & 50 \\
Candida albicans & 12.5 & 25 \\
Candida krusei & 12.5 & 50 \\
\hline
\end{tabular}

KEY: $0 *$ not determined

\section{CONCLUSION}

This study led to the isolation and characterization of a bioactive triterpene; betulinic acid. The in vitro anti-microbial screening of the isolated compound supports the ethno medicinal claim on the uses of Fadogia erythrophloea for the treatment of malaria, childhood fever, dysentery diarrhea, colic and constipation. It is therefore recommended that further studies should be carried out on the antimicrobial activity of the isolated compound on other microbes and also, more compounds (from the plant) should be isolated, characterized and their antimicrobial activity should be determined.

\section{Acknowledgement}

I give God the glory for the success of this research work. My g

\section{REFERENCES}

1. G. M. Cragg, D. J. Newman and K. M. Snader (1997), Natural products in drug discovery and development, Journal of Natural Products, 60, 52-60. 
2. D.J. Newman, G.M. Cragg and M.K. Snader (2000), The influence of natural products upon drugs, Natural Products Reports, 17, 215-234.

3. D.J. Newman, G.M. Cragg and M.K. Snader (2003), Natural products as sources of new drugs over the period 1981-2002, Journal of Natural Products, 66 (7), 1022-1037.

4. M. S. Butler (2004), The role of natural product chemistry in drug discovery, Journal of Natural Products, 67 (12), 2141-2153.

5. P. B. Mallikharjuna, L. N. Rajanna, Y. N. Seetharam and G. K. Sharanabasappa (2007), Phytochemical studies of Strychnos potatorum L.F. A medicinal plant, E-jour. Chem., 4(4), 510-518.

6. D. A. Dias, S. Urban and U. Roessner (2012), A historical overview of natural products in drug discovery, Metabolites, 2 , 303-336.

7. D. Martin and C. V. Nunez (2015), A review of Secondary Metabolites from Rubiaceae Species, Molecule, 20, 1342213495.doi: 10.3390.

8. M. E. Heitzman, C. C., Neto, Winiarz, E., Vaisberg, A. J. and G. B. Hammond (2005), Ethnobotany, Phytochemistry and Pharmacology of Uncaria (Rubiaceae), Phytochemistry, 66, 5-29.

9. J. B. Harborne (1984), Phytochemical Methods, Chapmann and Hall, London, 833.

10. E. Stahl (1969), Thin Layer Chromatography: A Laboratory Handbook, Second Edition, Springer, New York.

11. A. Nostro, M. P. Germano, V. Di Angelo, A. Marino and M. A. Cannattelli (2000), Letter of Applied Microbiology, 30, 379385.

12. A. Haque, A. M. M. Siddiqi, M. M. F. A. Rahman, M. C. Hasan and S. M. A. Chowdhury (2013), Isolation of betulinic acid and 2,3-dihydroxyolean-12-en-28-oic acid from the leaves of callistemon linearis, Dhaka. Univ. J. Sci, 61(2), 211212.

13. M. Sholinchin and K. Yamasaki (1980), ${ }^{13} \mathrm{C}$ Nuclear Magnetic Resonance of lupane-type triterpenes; lupeol, betulin and betulinic acid, Chem. Pharm. Bull, 28 (3), 1006-1008.

14. P. R. Murray, E. J. Baron, M. A. Pfaller, F. C. Tenover and R. H. Yolken (1999), Manual of Clinical Microbiology, American Society for Microbiology.1325, Masassachusetts Avenue, N.W, Washinton DC, pp 1687-1701.

15. T. D. Tripathi (2008), Essential of Medical Pharmacology, Jaypea Brothers Medical Publishers Ltd., B-3 WMCA house, 23 / 23b Ansari road, Daryaganji, New Delhi 11002 India, pp 481-482.

16. A. Michel (2004), Trees, Shrubs and Lianas of West African Dry Zones, CiradMargraf, Weikersheim, Germany, p 445.

17. J. C. P. Steele, D. C. Warhurst, G. C. Kirby, and M. S. J. Simmonds (1999), In vitro evaluation of betulinic acid as an antimalarial, Phytotherapy research, 13, 115-119.

18. P. Yogeeswari and D. Sriram (2005), Betulinic acid and its derivatives: A review on their biological properties, Current medicinal chemistry, 12, 657-666.

19. M. A. Innocente, S. N. T. Silva, N. L. Cruz, N. M. Moraes, P. Sonnet, G. Gosmann, S. R. C. Garcia and B. C. S. Gnoatto (2012), Synthesis and antiplasmodial activity of betulinic acid and ursolic acid analogues, Molecules, 17, 12003-120014.

20. K. J. Adesanwo, O. O. Makinde and A. C. Obafemi (2013), Phytochemical analysis and antioxidant activity of methanol extract and betulinic acid isolated from the roots of Tetracera potatoria, Journal of Pharmacy research, 30, 1-5. 


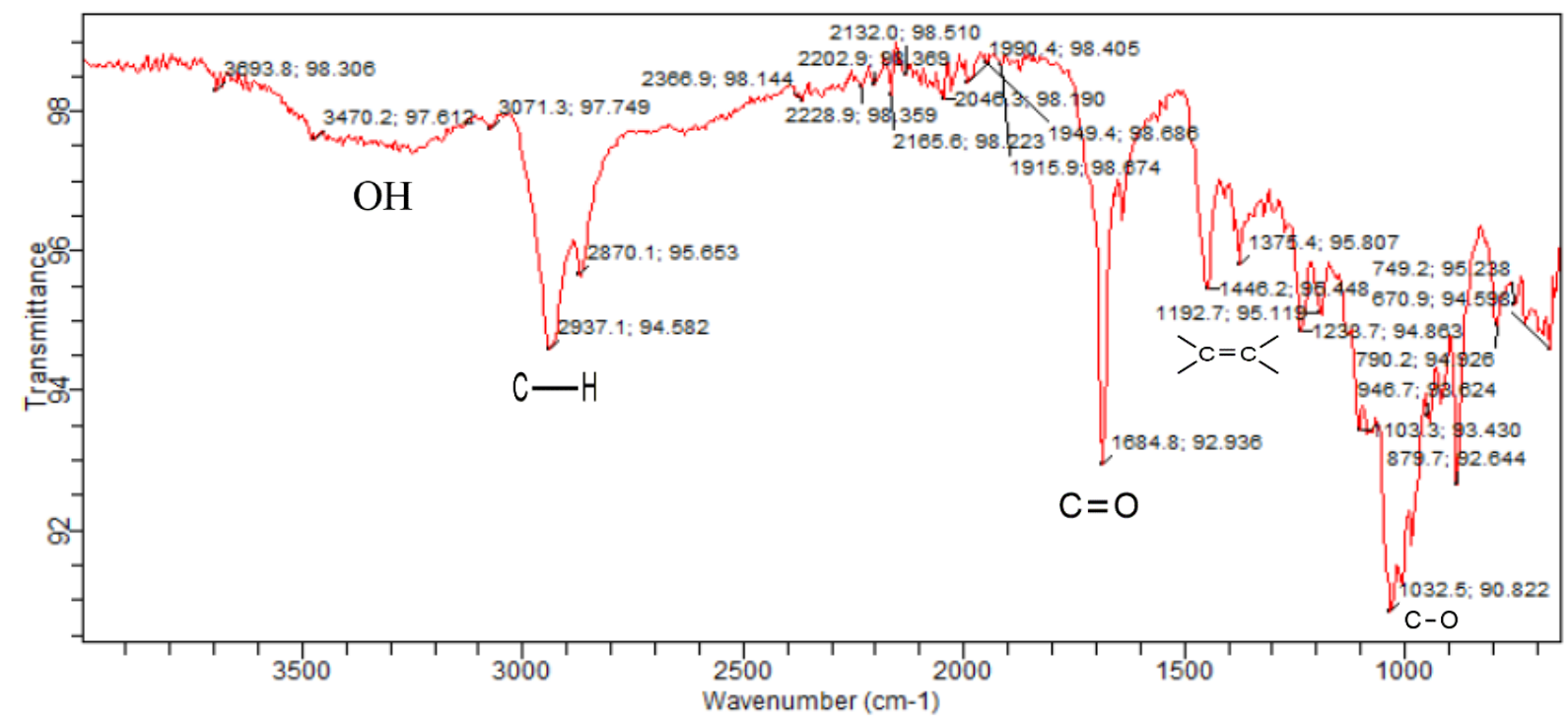

Figure 2: FTIR Spectrum of Compound JFE (betulinic acid)

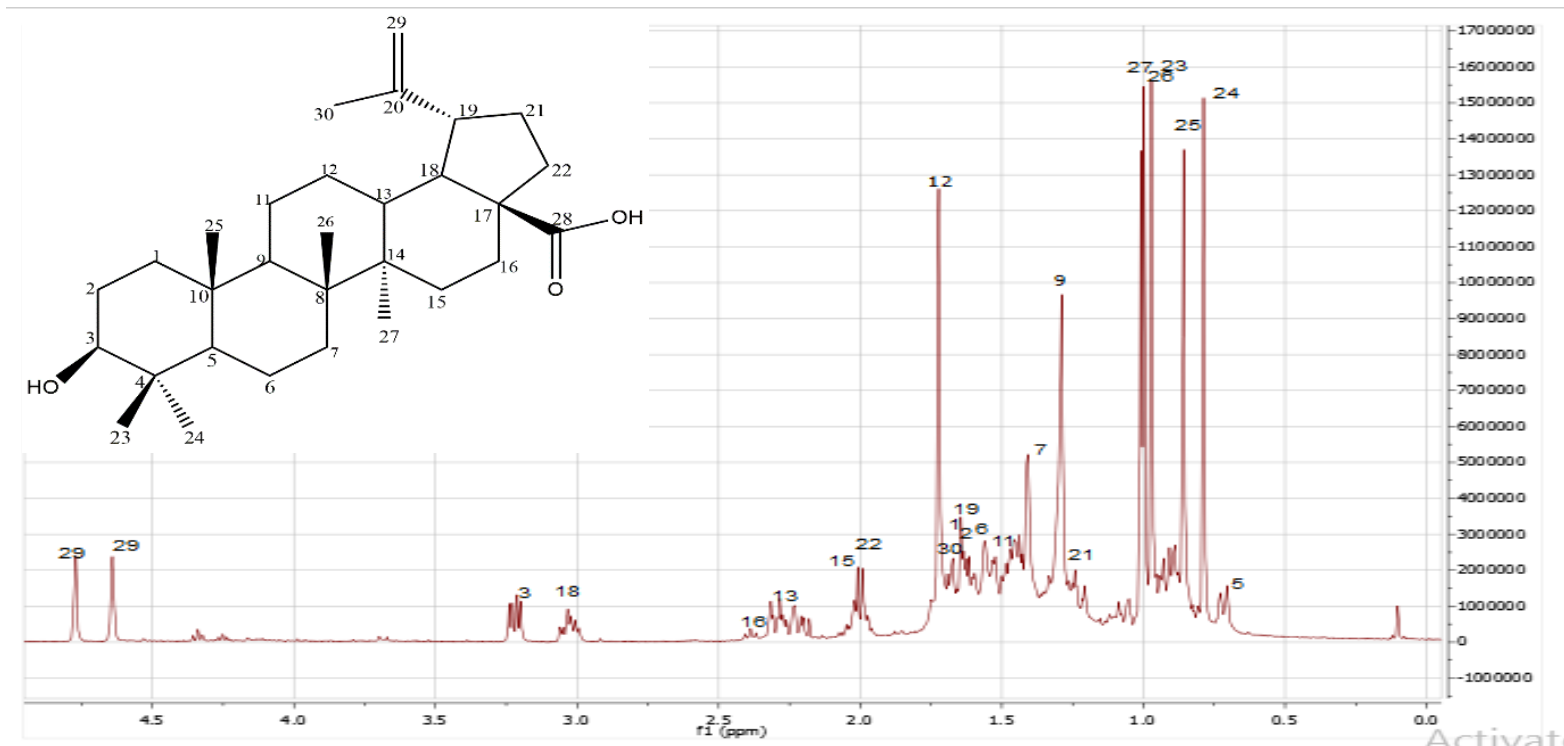

Figure 3: ${ }^{1} \mathrm{H}$ NMR spectrum of Compound JFE (betulinic acid) 


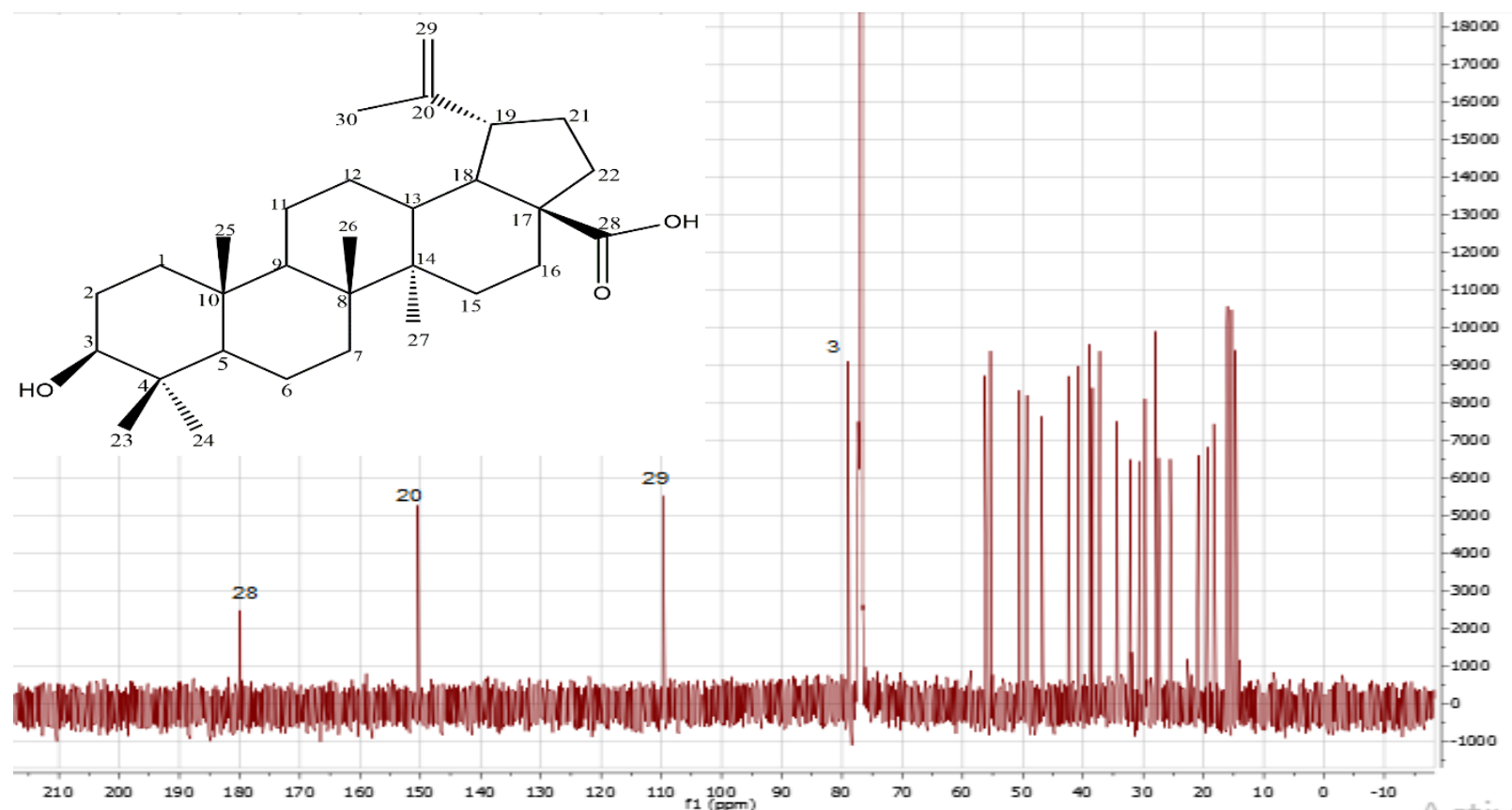

Figure 4: Decoupled ${ }^{13} \mathrm{C}$ NMR spectrum of Compound JFE (betulinic acid)

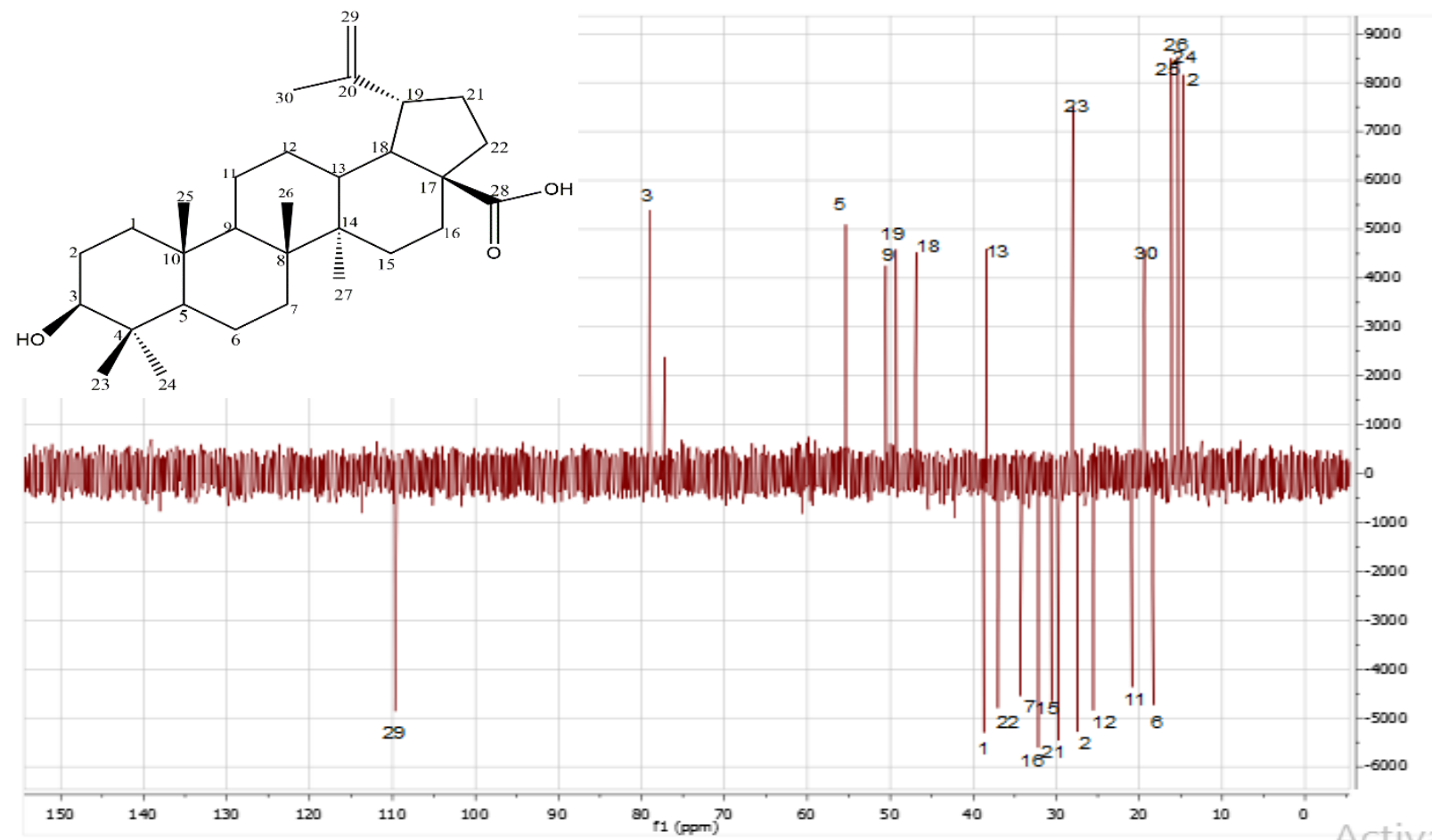

Figure 5: DEPT 135 spectrum of Compound JFE (betulinic acid) 